\title{
Type D personality and the degree of control of bronchial asthma
}

\author{
Andrzej Witusik ${ }^{1}$, Łukasz Mokros², Marcin Kosmalski², Michał Panek ${ }^{3}$, Katarzyna Nowakowska-Domagała ${ }^{4}$, \\ Kasper Sipowicz ${ }^{5}$, Piotr Kuna ${ }^{3}$, Tadeusz Pietras²
}

1Department of Psychology, Institute of Pedagogical Sciences, Faculty of Social Science, Piotrków Trybunalski Branch, Jan Kochanowski
University, Kielce, Poland
2Department of Clinical Pharmacology, Medical University of Lodz, Lodz, Poland
${ }^{3}$ Department of Internal Medicine, Asthma and Allergy, Medical University of Lodz, Lodz, Poland
${ }^{4}$ Department of Cognitive Science, Institute of Psychology, Faculty of Educational Sciences, University of Lodz, Lodz, Poland
${ }^{5}$ The Maria Grzegorzewska University, Institute of Special Education, Chair of Disability Studies, Warsaw, Poland

Adv Dermatol Allergol 2018; XXXV (4): 387-391

DOI: https://doi.org/10.5114/ada.2018.77670

\begin{abstract}
Introduction: Poor asthma control is probably associated with both biological and psychological factors. Type D pattern of behavior is characterized by negative emotionality and inhibition in social relationships. It was previously found to be associated with cardiovascular diseases.

Aim: To evaluate the correlation between the degree of asthma control and the severity of the components of type $D$ behavior pattern.

Material and methods: The research was conducted on a group of 117 subjects with bronchial asthma. The control group consisted of 32 healthy subjects. The degree of bronchial asthma control was determined using the Asthma Control Test. The D pattern of behavior was measured using the DS-14 questionnaire.

Results: The risk of type $D$ behavior pattern, defined as scoring at least 10 points in both scales (Negative Emotionality and Social Inhibition), was higher in subjects with uncontrolled asthma than in healthy individuals $(\mathrm{OR}=5.19 ; 95 \% \mathrm{Cl}: 1.74-15.44)$, those with partial control of asthma (OR $=6.04 ; 95 \% \mathrm{Cl}: 1.87-19.52)$ and subjects with good control of asthma $(\mathrm{OR}=8.46 ; 95 \% \mathrm{Cl}: 3.09-23.16)$. The severity of depressiveness correlated positively with the number of infections in the past year. Negative emotionality correlated positively with the number of infections and social inhibition.

Conclusions: Type D pattern of behavior may be associated with diagnosis and severity of asthma. Due to its link to poor control of asthma symptoms, a high level of negative emotionality among patients with asthma might be of particular interest to the clinicians.
\end{abstract}

Key words: negative emotionality, asthma control, depressiveness.

\section{Introduction}

The degree of control of bronchial asthma and its clinical course depend on biological factors (contraction of the airways, tendency to bronchial hyperreactivity) as well as psychological ones [1]. The fact that intensive stress induces the attack of dyspnea in subjects with a significant degree of bronchial hyperreactivity is commonly known [2]. In our previous papers, we have demonstrated that anxiety, depression and the structure of temperament are important in the clinical presentation of asthma [2]. Temperamental factors, according to the model developed by Strelau et al., correlate with the spirometric parameters of asthma and its severity [2]. Con- trary to expectations, type A personality, a well-known risk factor of cardiovascular diseases, proved to have no connection with the severity and course of bronchial asthma, which we have demonstrated in our studies [3].

Type $D$ pattern of behavior, also referred to as stress personality was described by Johan Denolleta, a clinical psychologist of the University of Tilburg in the Netherlands. Type D personality consists of two main dimensions, treated as relatively fixed personality traits, namely, negative emotionality and social inhibition [4]. Negative emotionality means the tendency to experience negative emotions such as anger, hostility or anxiety. Social inhibition is the tendency to restrain the

Address for correspondence: Łukasz Mokros MD, Department of Clinical Pharmacology, Medical University of Lodz, 22 Kopcinskiego St, 91-153 Lodz, Poland, phone: +48 426782 129, e-mail: lukasz.mokros@umed.lodz.pl Received: 17.02.2017, accepted: 20.06.2017. 
expression of these negative emotions and behaviors consistent with those emotions. Type $\mathrm{D}$ behavior is considered, like type A behavior pattern, to be a risk factor for the development of cardiovascular diseases [5]. The cause of behavior typical of type $D$ pattern is the fear of disapproval and rejection on the part of other people. The characteristics of subjects with type D personality include: a tendency to worry and feel the tension, low sense of security, a pessimistic view of the world, the feeling of being unhappy, a tendency to blame oneself, shyness and weak ties with other people, discomfort in the presence of other people. A characteristic feature of type $D$ pattern of behavior is a tendency to depressive reactions and the lack of use of social support [6]. Type $D$ personality, like other patterns of behavior such as A, B or $C$, are permanent personality traits favoring specific behaviors. These patterns of personality develop as a result of the interaction of the temperamental factors and social learning $[7,8]$. It is interesting whether the degree of asthma control is associated with the occurrence of type $D$ pattern of behavior. This is a legitimate question in view of the fact that both depressiveness and anxiety correlate with the severity and degree of control of bronchial asthma $[9,10]$. The answer to this question will help to develop in the future the behavioral profile of subjects affected with bronchial asthma.

\section{Aim}

The aim of the research was to evaluate the correlation between the degree of asthma control and the severity of the components of type $\mathrm{D}$ behavior pattern - anxiety and depression.

\section{Material and methods}

The research was conducted on a group of 117 subjects with bronchial asthma aged 20-60 years, patients of the outpatient asthma treatment department of Norbert Barlicki Memorial University Clinical Hospital No. 1. The control group consisted of 32 healthy individuals.
Patients with cancer, chronic obstructive pulmonary disease, systemic connective tissue diseases, past acute coronary episode during the last 6 months, and those experiencing intensive stress due to mourning, surgery or job loss, were excluded from the study. Subjects above 60 years of age were also excluded.

The degree of bronchial asthma control was determined using the Asthma Control Test $[11,12]$. In the Asthma Control Test, consisting of five questions, the score of 25 points was regarded as good control of asthma, the result of 20-24 points - as partial control and 20 points or less - as poor control. Poor control of asthma was diagnosed in 31 subjects, partial control in 27, and good control in 60. The studied groups did not differ significantly in the demographic variables, as presented in Table 1 . The pattern of behavior (D) was measured using the Polish standardized version of the DS-14 questionnaire developed by Juczyński and Ogińska-Bulik [13]. The test results determine two factors - Negative Emotionality and Social Inhibition. Theoretically, up to 28 points can be scored in either of the dimensions. A subject who scored at least 10 points in either of the two dimensions is considered to have type $D$ personality. The severity of depressiveness was measured using the Polish version of Beck Questionnaire (Beck Depression Inventory - BDI) [14]. The age of the patient and the number of infectious exacerbations over the last year were specified by means of a questionnaire survey of own design. The research project was approved by the Bioethics Committee of the Medical University in Łódź, number of approval: RNN/133/09.

\section{Statistical analysis}

The odds ratios and confidence intervals were calculated using the online calculator available on the website http://www.hutchon.net [15]. Statistical analysis was performed using the Statistica $12 \mathrm{PL}$ software package (Tulsa, OK, USA and Krakow, Poland). The selection of statistical tests was based on the distribution of variables and on the homogeneity of variance, verified with the Shapiro-Wilk test and the Levene test, respectively. For comparisons between groups, ANOVA with post-hoc

Table 1. Comparison of variables included in the analysis between healthy subjects and patients with asthma controlled, partially controlled and poorly controlled

\begin{tabular}{|c|c|c|c|c|c|}
\hline Parameter & Healthy $(N=32)$ & Full control $(N=60)$ & Partial control $(N=27)$ & Poor control $(N=31)$ & $P$-value \\
\hline Age & $31.94 \pm 10.19$ & $34.13 \pm 9.94$ & $32.22 \pm 8.05$ & $36.16 \pm 9.15$ & 0.27 \\
\hline Infections & $0(0-0.5)^{a, d}$ & $1(0-1)^{\mathrm{a}, \mathrm{d}}$ & $2(1-2)$ & $2(1-3)$ & $<0.001$ \\
\hline BDI & $8.03 \pm 2.28^{a}$ & $7.75 \pm 3.79^{a}$ & $9.07 \pm 5.20^{b}$ & $13.23 \pm 5.24$ & $<0.001$ \\
\hline \multicolumn{6}{|l|}{ DS14: } \\
\hline Neg emot & $8.34 \pm 2.54^{\mathrm{a}}$ & $7.90 \pm 3.47^{a}$ & $8.78 \pm 2.91^{\mathrm{b}}$ & $11.97 \pm 4.74$ & $<0.001$ \\
\hline Soc inhib & $9.66 \pm 7.48$ & $8.42 \pm 3.98$ & $9.89 \pm 3.51$ & $11.26 \pm 3.61$ & 0.07 \\
\hline Total & $18.00 \pm 8.95^{c}$ & $16.32 \pm 6.89^{b}$ & $18.67 \pm 6.09$ & $23.23 \pm 7.71$ & $<0.001$ \\
\hline
\end{tabular}

Presented as mean \pm standard deviation or median (upper-lower quartile) with significance level $p$ for the analysis of variance (or Kruskal-Wallis test in the case of the "infection" variable). BDI-Beck Depression Inventory, DS14 - Type D Personality Scale, neg emot - negative emotionality subscale, soc inhib - social inhibition subscale. ${ }^{a} p<0.001$ in post hoc vs. no control, ${ }^{b} p<0.01$ in post hoc vs. no control, $c p<0.05$ in post hoc vs. no control, ${ }^{c} p<0.05$ in post hoc vs. partial control. 
Table 2. The matrix of correlations between continuous variables of interest. Pearson correlation coefficients presented

\begin{tabular}{|c|c|c|c|c|c|}
\hline \multirow[t]{2}{*}{ Variable } & \multirow[t]{2}{*}{ Age } & \multirow[t]{2}{*}{ Infections } & \multirow[t]{2}{*}{ BDI } & \multicolumn{2}{|c|}{ DS14 } \\
\hline & & & & Neg emot & Soc inhib \\
\hline Infections & 0.013 & & & & \\
\hline BDI & 0.177 & $0.292^{\mathrm{a}}$ & & & \\
\hline \multicolumn{6}{|l|}{ DS14: } \\
\hline Neg emot & 0.066 & $0.250^{\mathrm{a}}$ & $0.644^{a}$ & & \\
\hline Soc inhib & 0.113 & 0.090 & $0.471^{a}$ & $0.595^{b}$ & \\
\hline Total & 0.103 & 0.179 & $0.612^{b}$ & $0.863^{b}$ & $0.919^{b}$ \\
\hline
\end{tabular}

Significance levels presented concern the results after Benjamini-Hochberg correction. ${ }^{a} p<0.01,{ }^{b} p<0.001, B D I-B e c k$ Depression Inventory, DS-14-type D Personality Scale, neg emot - negative emotionality subscale, soc inhib-social inhibition subscale.

Tukey test for subgroups with different numbers of subjects was used. In case of non-parametric distribution of the variables, Kruskal-Wallis test with post-hoc multiple comparisons test was used for inter-group comparisons. The association between two continuous variables was evaluated using the Pearson correlation coefficient. To avoid making type one error, the Benjamini-Hochberg correction was applied [16].

\section{Results}

The severity of depressiveness (depression) was demonstrated to be greater in the group of subjects with poor asthma control as compared to the other groups surveyed. The other groups did not differ significantly from each other in the severity of depressiveness (Table 1). The number of infections in the last year has proved to be significantly higher in the group of individuals with poorly controlled and partially controlled asthma in comparison to those with the well-controlled asthma and to healthy individuals (Table 1). Negative Emotionality, like depressiveness, was greater in the group of subjects with poor asthma control as compared with the other groups. In contrast, no inter-group differences in the intensity of the Social Inhibition factor were found statistically significant. The total result of the scores obtained with DS-14 showed a significantly higher result in people with uncontrolled and partially controlled asthma in comparison with the group with good control of the disease.

The risk of type $D$ personality defined as scoring at least 10 points in both scales (Negative Emotionality and Social Inhibition) was higher in subjects with uncontrolled asthma than in healthy individuals (odds ratio $(O R)=5.19 ; 95 \%$ confidence interval $(95 \% \mathrm{Cl})$ : 1.74-15.44). Subjects with partially controlled and wellcontrolled asthma did not demonstrate a greater likelihood of a type $\mathrm{D}$ behavior pattern than healthy individuals $(\mathrm{OR}=0.75 ; 95 \% \mathrm{Cl}: 0.23-2.49$ and $\mathrm{OR}=1.5 ; 95 \% \mathrm{Cl}$ : 0.49-4.51). No degree of asthma control was associated with a greater risk of type $D$ behavior pattern than in healthy individuals $(\mathrm{OR}=1.29,95 \% \mathrm{Cl}$ : $0.53-3.16)$. The risk of having type D personality was higher for subjects with poorly controlled asthma versus individuals with partial control of asthma (OR $=6.04 ; 95 \% \mathrm{Cl}: 1.87-19.52)$ and for subjects with poorly controlled asthma versus those with good control of asthma $(\mathrm{OR}=8.46 ; 95 \% \mathrm{Cl}$ : 3.09-23.16).

The age of the subjects did not correlate significantly with other analyzed variables (Table 2). The severity of depressiveness correlated positively with the number of past infections during the last year. Depressiveness correlated also with negative emotionality and social inhibition, as well as with the total number of possible points scored in the DS-14 test. Negative emotionality correlated positively with the number of infections and social inhibition. It is interesting that social inhibition did not correlate with the number of infections, in contrast to negative emotionality (Table 2).

\section{Discussion}

The research has demonstrated that poorly controlled asthma is associated with greater severity of depressiveness, as well as with the severity of Negative Emotionality. Poor asthma control is associated with a higher probability of type D personality as compared with healthy subjects and subjects with well and partially controlled asthma. A question arises whether poor asthma control is the result or the cause of type D behavior pattern presented. Type D personality is, like type A personality, a negative health predictor, developed for coronary heart disease. Behavior pattern $\mathrm{D}$ has been proven to be an independent risk factor for recurrent myocardial infarctions [17, 18] and overall post-infarction mortality [18-20]. Single reports indicate also that type D pattern of behavior correlates with the severity of asthma symptoms, which has been confirmed by our research on the association between the degree of asthma control and the occurrence of type D personality [19]. Poor control of asthma is associated with an increased risk of infections of the respiratory system [20]. At the time of infection in the course of bronchial asthma, numer- 
ous proinflammatory cytokines produced by several cell types are secreted, which correlates with the severity of depressiveness, which has been demonstrated in particular with respect to interleukin 5 [21]. Our own research has shown that the level of mRNA for interleukin 15 in patients with bronchial asthma correlates with the temperamental personality traits [22], and that there is a relationship between asthma patients' personality and a polymorphism of the gene coding for the glucocorticosteroid receptor [9]. Depressiveness is often associated with anxiety, which, especially in the form of attacks, can induce bronchospasm in the course of asthma [23]. Bronchial contraction is the result of both hyperventilation and exposure to cold air as well as regulation with mediators of the autonomic system innervating the bronchi $[23,24]$. A shortcoming of our research work is the lack of measurement of anxiety as a state, although it is well known to correlate with the severity of depressiveness as a component of the neuroticism superfactor according to Eysenck's model of personality or the Big Five model [7, 8]. We have demonstrated the association between anxiety and depressiveness in patients with asthma in many of our other publications [1, 3]. It has been suggested that increased central respiratory drive correlating with neuroticism and medication arouses the subjective feeling of breathlessness and induces bronchospasm, which is automatically associated with poor control of asthma [25]. Depressive subjects with type D personality pay less attention to taking prescribed medications regularly. It has been shown that irregular use of medications in young people with asthma is associated with type D behavior [26]. Irregular treatment, especially with respect to the use of inhaled steroids, can result in incomplete control of the symptoms of bronchial asthma. A vicious circle mechanism can be suggested - the infection favors the dyspnea and depressiveness. Depressiveness induces anxiety and attacks of dyspnea. Negative emotionality associated with depressiveness (both factors studied in our work) means in turn worse asthma control and lower motivation to start treatment [27]. The proposed correlations explain well the observed associations that occur between poor control of bronchial asthma, the severity of depressiveness, negative emotionality, the number of infections in the last year and type D personality. However, this is an attempt to clarify this issue which requires empirical validation.

The fact that the studied groups do not differ in the Social Inhibition dimension is noteworthy. This is even more interesting in view of the fact that its severity correlates with both depressiveness and negative emotionality (Table 2). Conceivably, the impact of withdrawal and avoidance of the expression of negative emotions, as well as the behavioral aspect of type D personality on the degree of control of bronchial asthma is too little [28]. The correlation coefficient between the two component factors of type $D$ personality obtained in our study $(r=0.595)$ is similar to that obtained by the authors of the Polish standardization of the test $(r=0.64)$ [13]. The behavioral aspect of type $D$ personality has a probably negligible relation with asthma control, as we have demonstrated in our studies.

The shortcoming of our research, alongside the lack of measurement of the severity of anxiety as a trait and anxiety as a state is non-random character of the study groups. The distribution of the numbers of subjects with various degrees of asthma control reflect the populations of patients seeking medical assistance in specialized clinics, and not the population of subjects with the disease. It is possible that in a random sample of the population, the correlations between the tested variables might be different. Too small size of the groups prompts to formulate the conclusions with caution and to repeat the study on a random sample of a large population. It would also be useful to analyze the differences between clinical and cellular phenotypes of asthma, and age at the onset of the disease, the presence of allergy or hypersensitivity to aspirin. Our study, however, is the first one that demonstrates so clearly the association of type $\mathrm{D}$ personality not only with ischemic heart disease, but also with poorly controlled bronchial asthma

\section{Conclusions}

Subjects with poorly controlled asthma present a type D pattern of behavior more frequently than those with partially controlled or well-controlled asthma and healthy individuals. Poor asthma control is associated with a higher severity of depressiveness, negative emotionality and a greater number of infections than in partially and well-controlled asthma and in healthy subjects. The severity of the social inhibition factor does not differentiate the studied groups.

\section{Acknowledgments}

Andrzej Witusik and Łukasz Mokros are equivalent. The contributions of the first two authors are equivalent and account for $80 \%$ of the contributions to this research.

\section{Conflict of interest}

The authors declare no conflict of interest.

\section{References}

1. Panek M, Pietras T, Witusik A, et al. Identification and association of relationships between selected personal and environmental factors and formal components of temperament and strategies of coping with stress in asthmatic patients. Physiol Behav 2015; 149: 269-78.

2. Panek M, Kuna P, Witusik A, et al. Temperament and stress coping styles in bronchial asthma patients. Adv Dermatol Alergol 2016; 33: 469-74. 
3. Witusik A, Pietras T. Personality and behavioral factors in the clinical manifestation of bronchial asthma (in Polish). Piotrków Scientific Publishing House, Piotrków Trybunalski 2011.

4. Mols F, Denollet J. Type D personality among non-cardiovascular patient populations: a systematic review. Gen Hosp Psychiatry 2010; 32: 66-72.

5. Denollet J, Schiffer AA, Spek V. A general propensity to psychological distress affects cardiovascular outcomes: evidence from research on the type $D$ (distressed) personality profile. Circ Cardiovasc Qual Outcomes 2010; 3: 546-57.

6. van Dooren FE, Verhey FR, Pouwer F, et al. Association of type $D$ personality with increased vulnerability to depression: is there a role for inflammation or endothelial dysfunction? The Maastricht Study. J Affect Disord 2016; 189: 118-2.

7. Strelau J. Temperament as a regulator of behavior in fiftyyear research perspective [Polish]. Gdansk Psychology Publishing Company, Gdansk 2006.

8. Strelau J. Individual differences - history - determinants - applications [Polish]. Scholar Publishing House, School of Social Psychology, Warsaw 2014.

9. Panek M, Pietras T, Szemraj J, Kuna P. Association analysis of the glucocorticoid receptor gene (NR3C1) haplotypes (ER22/23EK, N363S, Bcll) with mood and anxiety disorders in patients with asthma. Exp Ther Med 2014; 8: 662-70.

10. Slavich GM, Irwin MR. From stress to inflammation and major depressive disorder: a social signal transduction theory of depression. Psychol Bull 2014; 140: 774-815.

11. www.ginasthma.org/2016.

12. Juniper EF, O'Byrne PM, Guyatt GH, et al. Development and validation of a questionnaire to measure asthma control. Eur Respir J 1999; 14: 902-7.

13. Juczyński Z, Ogińska-Bulik N. Tools measuring stress and coping with stress [Polish]. Psychological Tests Laboratory, Warsaw2009.

14. Wciorka J, Pużyński S. Tools for evaluation of mental condition. In: Psychiatry. Vol. I. Fundamentals of psychiatry. Rybakowski J, Pużyński S, Wciorka J (eds.). Urban \& Partner, Wrocław 2010; 413-76 [Polish].

15. http://www.hutchon.net/ConfidOR.htm

16. Szymczak W. Fundamentals of statistics for psychologists. Diffin, Warsaw 2010 [Polish].

17. Kupper N, Denollet J. Explaining heterogeneity in the predictive value of type $D$ personality for cardiac events and mortality. Int J Cardiol 2016; 224: 119-24.

18. Condén E, Rosenblad A, Wagner P, et al. Type D personality an independent risk factor for recurrent myocardial infarction or all-cause mortality in post-acute myocardial infarction patients? Eur J Prev Cardiol 2017; 24: 522-33.

19. Kim SR, Kim HK, Kang JH, et al. Does type D personality affect symptom control and quality of life in asthma patients? J Clin Nurs 2015; 24: 739-48.

20. Carr TF, Kraft M. Chronic infection and severe asthma. Immunol Allergy Clin North Am 2016; 36: 483-502.

21. Elomaa AP, Niskanen L, Herzig KH, et al. Elevated levels of serum IL-5 are associated with an increased likelihood of major depressive disorder. BMC Psychiatry 2012; 12: 2.

22. Panek M, Jonakowski M, Zioło J, et al. Identification of relationships between interleukin 15 mRNA and brain-derived neurotrophic factor II mRNA levels with formal components of temperament in asthmatic patients. Mol Neurobiol 2016; 54: 1733-44.

23. Li HL, He XL, Liang BM, et al. Anxiety but not depression symptoms are associated with greater perceived dyspnea in asthma during bronchoconstriction. Allergy Asthma Proc 2015; 36: 447-57.

24. Weiler JM, Brannan JD, Randolph CC, et al. Exercise-induced bronchoconstriction update - 2016. J Allergy Clin Immunol 2016; 138: 1292-5.

25. Mahler DA, O'Donnell DE. Recent advances in dyspnea. Chest 2015; 147: 232-41.

26. van de Ven MO, Witteman CL, Tiggelman D. Effect of type D personality on medication adherence in early adolescents with asthma. J Psychosom Res 2013; 75: 572-6.

27. Pilipenko N, Karekla M, Georgiou A, et al. Impact of psychiatric illness upon asthma patients' health care utilization and illness control. Are all psychiatric comorbidities created equal? Psychol Health Med 2016; 21: 787-99.

28. McCullough AR, Ryan C, Macindoe C, et al. Behavior change theory, content and delivery of interventions to enhance adherence in chronic respiratory disease: a systematic review. Respir Med 2016; 116: 78-84. 